\title{
Cardiac magnetic resonance in acute rheumatic fever
}

\author{
Diana Lamprea Sepulveda ${ }^{6,4}$, Eveline B Calado ${ }^{3,5}$, Eugênio Albuquerque ${ }^{6}$, Alfredo Rodrigues ${ }^{1,3}$, \\ Maria Eduarda M Siqueira ${ }^{1,3}$, Cleusa Lapa ${ }^{2,5}$, Lurildo Saraiva ${ }^{5}$, Roberta Mochiduky ${ }^{3}$, Dario Sobral ${ }^{6}$, \\ Marly Uellendahl $1^{1,3^{*}}$
}

From 16th Annual SCMR Scientific Sessions

San Francisco, CA, USA. 31 January - 3 February 2013

\section{Background}

Acute rheumatic carditis is a pancarditis in which the involvement of the pericardium and endocardium is usually confirmed by echocardiography. However, the myocardium involvement has been controversial and difficult to diagnose. We think that Cardiac Magnetic Resonance adds important information about the involvement of the myocardium in acute rheumatic fever, especially for myocardial delayed enhancement(MDE) that can detect myocardial inflammation and injury.

\section{Methods}

We enrolled patients admitted between January and December 2010 in two different hospitals of the northeastern of Brazil with acute rheumatic fever. The patients were diagnosed according to the revised Jones Criteria for acute rheumatic fever and the World Health Organization criteria for rheumatic carditis. All the patients underwent cardiac magnetic resonance, using a1.5 Tesla scanner (Espree-Siemens, Muenchen, Germany) in two pulse sequences: a cine magnetic resonance- SSFP( Steady State Free Precession) to evaluate cardiac morphology and ventricular function, and myocardial delayed enhancement with a Phase-Sensitive Inversion Recovery (PSIR) sequence, after $0,02 \mathrm{mmol} / \mathrm{Kg}$ of gadolinium infusion to evaluate myocardial involvement. The images were analyzed by CMR- 42 software.

\section{Results}

We evaluated 18 patients with a mean age of $14,44( \pm 4,80)$ years old, 9 males and 9 females. There was no significant differences of age between males (14.88 \pm 5.4 years $)$ and

\footnotetext{
${ }^{1}$ Cardiology, UNIFESP, São Paulo, Brazil

Full list of author information is available at the end of the article
}

females $(14.00 \pm 4.3$ years $), p=0.68$. Cardiac magnetic resonance imaging identified pericardial effusion and mitral valvular thickening in all 18 patients (100\%), aortic valvular thickening in 17 patients $(94,44 \%)$ right ventricular dysfunction in 8 patients $(44,44 \%)$ and lef ventricular dysfunction in 5 patients (27,77\%). MDE was present in all the patients and was characterised by a diffuse, mesocardial and heterogeneous pattern. We observed a negative correlation between MDE mass and left ventricular ejection fraction $(r=-0,63 ; p=0,0050)$. In regard to gender we found a higher average of MDE mass in males( 23,90 \pm $8,86)$ compared to females $(14,44 \pm 4,66), \mathrm{p}=0,0151$; with no significant statistical difference on the global myocardial mass evaluated $(\mathrm{p}=0,054)$. Right ventricular dysfunction is

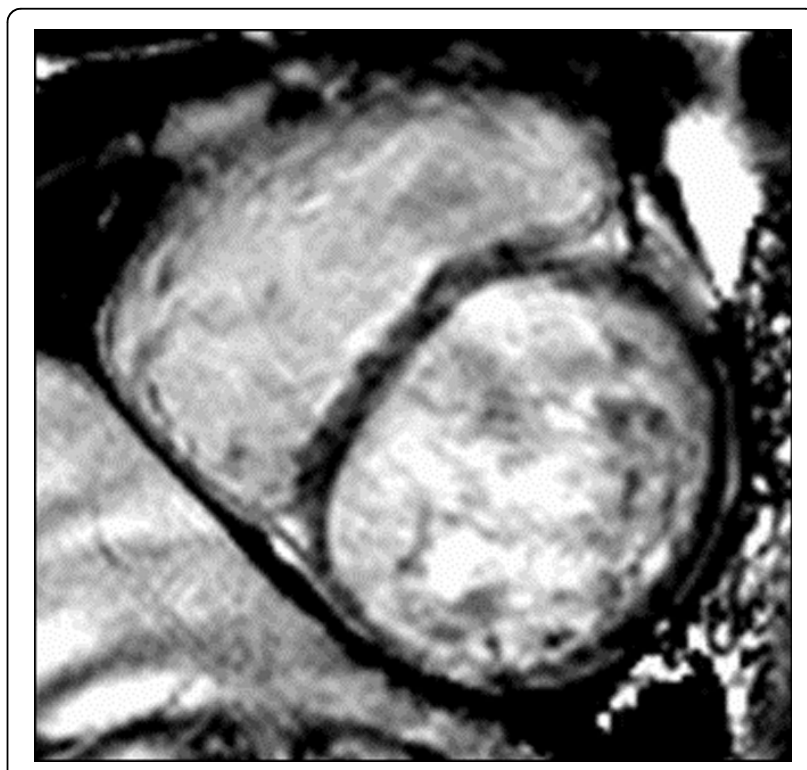

Figure 1 


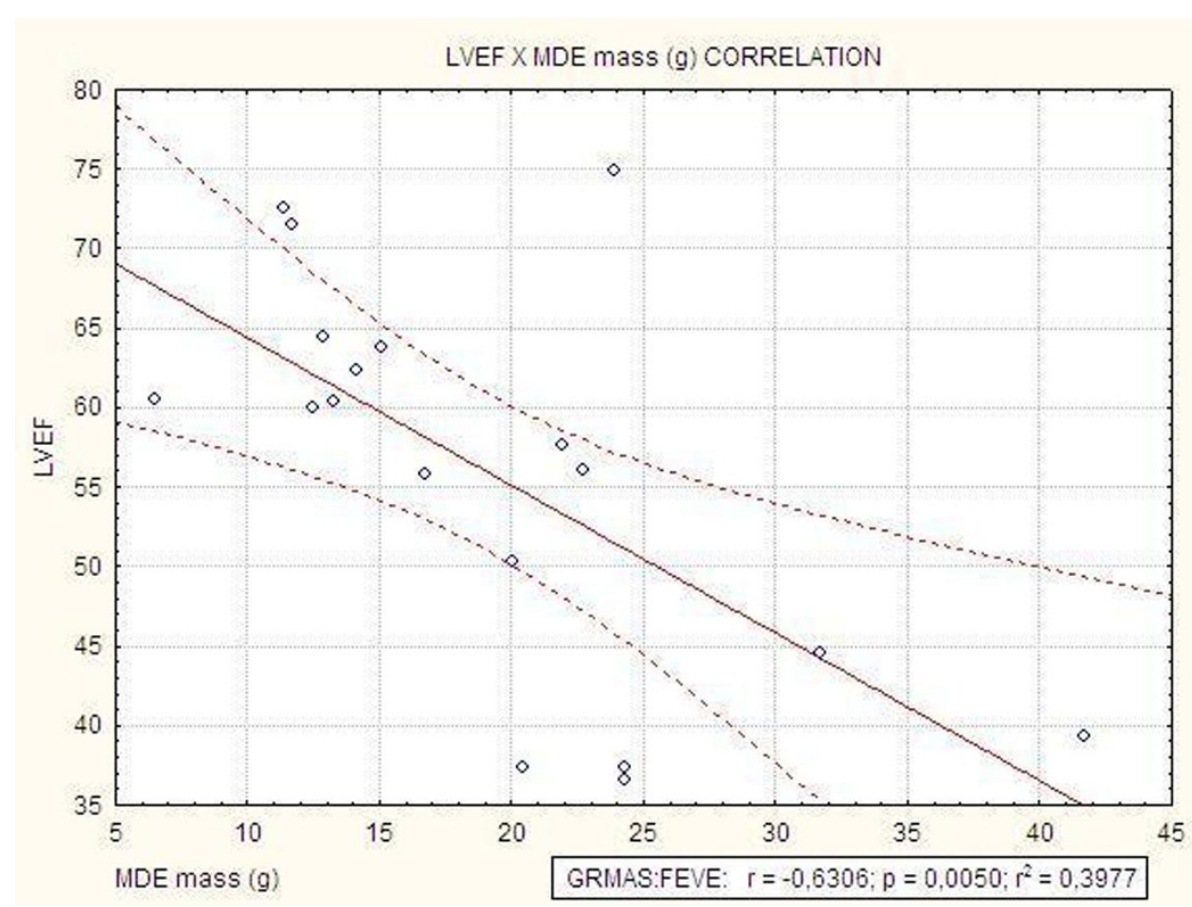

Figure 2

associated with pulmonary hypertension evaluated by echocardiography $(\mathrm{p}=0,0415)$.

\section{Conclusions}

Cardiac magnetic resonance imaging with gadolinium identified a typical inflammation pattern of MDE in acute rheumatic carditis and a negative correlation of the MDE mass and left ventricular function. Besides the small number of patients the gender differences of MDE mass may represent a more extensive inflammatory involvement in males.

\section{Funding}

Brazilian Society of Cardiology.

\section{Author details}

${ }^{1}$ Cardiology, UNIFESP, São Paulo, Brazil. ${ }^{2}$ Cardiology, IMIP, Recife, Brazil.

${ }^{3}$ Radiology, Delboni/DASA, São Paulo, Brazil. ${ }^{4}$ Cardiology, Real Hospital Portugës, Recife, Brazil. ${ }^{5}$ Cardiology, UFPE, Recife, Brazil. ${ }^{6}$ Cardiology, ProcapeUPE, Recife, Brazil.

Published: 30 January 2013

doi:10.1186/1532-429X-15-S1-O23

Cite this article as: Sepulveda et al.: Cardiac magnetic resonance in

acute rheumatic fever. Journal of Cardiovascular Magnetic Resonance 2013

15(Suppl 1):O23.
Submit your next manuscript to BioMed Central and take full advantage of:

- Convenient online submission

- Thorough peer review

- No space constraints or color figure charges

- Immediate publication on acceptance

- Inclusion in PubMed, CAS, Scopus and Google Scholar

- Research which is freely available for redistribution 